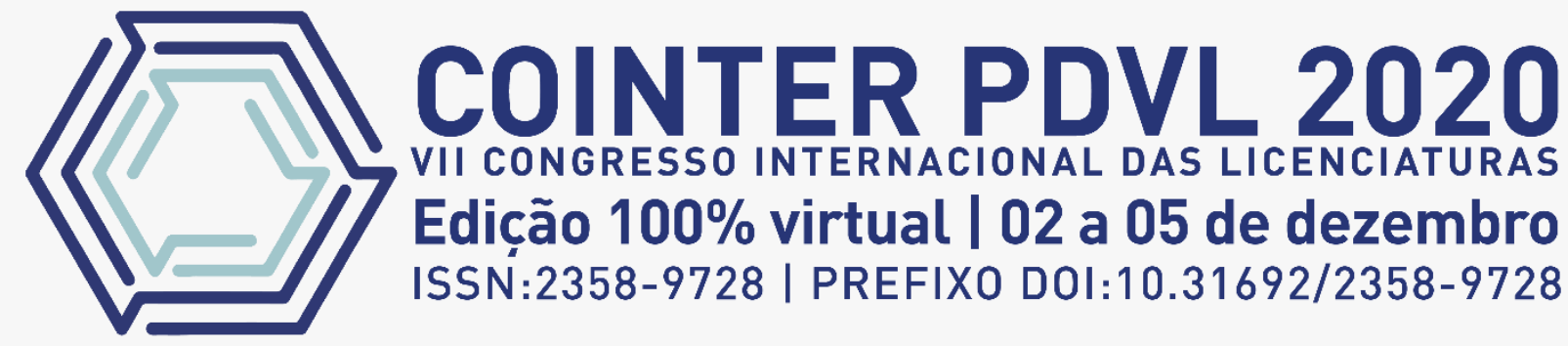

\title{
HISTÓRICO DE IDAS E VINDAS NO ENSINO OFICIAL DE LÍNGUA ESPANHOLA ACENTUA O SABOR DE INCERTEZA NO ENSINO E NA FORMAÇÃO DE PROFESSORES
}

\author{
HISTÓRICO DE IDAS Y VUELTAS EN LA ENSEÑANZA OFICIAL DE LENGUA \\ ESPAÑOLA ACENTÚA EL SABOR A INCERTIDUMBRE EN LA ENSEÑANZA Y \\ EN LA FORMACIÓN DE PROFESORES
}

\section{HISTORY OF ROUNDS AND RETURNS IN THE OFFICIAL TEACHING OF SPANISH LANGUAGE ACCENTUATES THE FLAVOR TO UNCERTAINTY IN THE TEACHING AND IN THE TEACHER TRAINING}

\author{
Apresentação: Comunicação Oral \\ Maria Trinidad Pacherrez Velascoํ; Duana Ravena dos Santos Vieira²
}

DOI: https://doi.org/10.31692/2358-9728.VIICOINTERPDVL.0432

\begin{abstract}
RESUMO
Neste trabalho, propomos refletir sobre a grave implicação que a história de idas e vindas da língua espanhola à obrigatoriedade do seu ensino teve ao longo de todos os tempos em que esteve envolvida. Essa mesma legalidade acabou afetando, inicialmente, positivamente, avaliando as razões geográficas e econômicas que incumbiam ao Brasil, bem como negativamente, posteriormente, quando se virou as costas e a obrigação de sua oferta foi retirada, dando um " retirar e colocar "aberto no ensino do espanhol e também na formação de profissionais, que nos chega até os dias de hoje, bamboleando a importância de seu ensino de acordo com o entendimento do governo no poder. Abordamos este tema com apoio em estudos bibliográficos e documentais, dialogando com autores como Abio (2016); Sedycias (2005); Gonzales (2008) e Fernández (2005) e refletindo sobre leis, resoluções, decretos, diretrizes técnicas e outros documentos oficiais do Ministério da Educação e Cultura do Brasil. Tomamos como ponto de partida um panorama de legislação que se inicia em 1942 e chega a 2020 e abordamos a intersecção entre o ensino e a formação docente, apresentando benefícios e malefícios que de fato exigem reflexão e busca de soluções que dêem estabilidade a este conhecimento que resulta em benefício para a sociedade como um todo, visto que os aspectos turísticos, sociais e econômicos representam espaço para o crescimento do país e a realização de vidas. Concluímos que a instabilidade quanto à presença da língua espanhola no sistema educacional brasileiro é notoriamente prejudicial à sociedade e que em certos momentos não parece um conhecimento de peso; Além disso, é perceptível a falta de documentos oficiais contendo argumentos que justifiquem a alta oscilação histórica que o ensino do espanhol sempre apresentou.
\end{abstract}

Palavras-chave: Idas e voltas, Incerteza, Ensino de Língua Espanhola, Formação de professores.

\footnotetext{
1 Professora Doutora, Instituto Federal de Educação, Ciência e Tecnologia do Rio Grande do Norte, maria.velasco@ifrn.edu.br

2 Professora Especialista, Instituto Federal de Educação, Ciência e Tecnologia do Maranhão, IFMA, Campus Avançado Carolina, duana.vieira@ifma.edu.br
} 


\section{RESUMEN}

En este trabajo, nos proponemos reflexionar sobre la severa implicancia que el histórico de idas y vueltas de la lengua española a la obligatoriedad de su enseñanza ha tenido a través de todos los tiempos en que esta haya estado involucrada. Esa misma legalidad terminó afectando, de inicio, positivamente, valorando las razones geográfica e económica que incumbían a Brasil, así como de forma negativa, más tarde, cuando se le dio la espalda y se le retiró la obligatoriedad de su oferta, dándose un "quita y pon" abierto en la enseñanza de español y también en la formación de profesionales, que nos llega hasta la actualidad, bamboleando la importancia de su enseñanza de acuerdo con el entendimiento del gobierno de turno. Abordamos este tema con respaldo en estudios bibliográficos y documentales, dialogando con autores como Abio (2016); Sedycias (2005); Picanço (2003), Gonzales (2008) e Fernández (2005) y reflexionando a partir de leyes, resoluciones, decretos, orientaciones técnicas y otros documentos oficiales del Ministerio de Educación y Cultura brasileño. Tomamos como punto de partida un panorama de legislaciones que inicia en 1942 y llega a 2020 e abordamos la intersección entre la enseñanza y la formación del profesorado presentando beneficios y perjuicios ocasionados que llaman de hecho a una reflexión y búsqueda de soluciones que den estabilidad a este conocimiento que resulta en un beneficio para la sociedad como un todo, pues aspectos de cuño turístico, social y económico suponen espacio para el crecimiento del país y realización de vidas. Concluimos que la inestabilidad respecto a la presencia de la lengua española en el sistema educacional brasileño perjudica notoriamente a la sociedad y parece no ser un conocimiento de peso en determinados momentos; además, es perceptible la carencia de documentos oficiales que contengan argumentos que justifiquen la alta oscilación histórica que la enseñanza de español presenta desde siempre.

Palabras Clave: Idas y vueltas, Incertidumbre, Enseñanza de Lengua Española, Formación de profesores.

\section{ABSTRACT}

In this work, we propose to reflect on the severe implication that the history of comings and goings of the Spanish language to the obligatory nature of its teaching has had throughout all the times in which it has been involved. That same legality ended up affecting, initially, positively, evaluating the geographical and economic reasons that were incumbent on Brazil, as well as negatively, later, when the back was turned and the obligation of its offer was withdrawn, giving a "remove and put "open in the teaching of Spanish and also in the training of professionals, which reaches us to this day, wavering the importance of its teaching in accordance with the understanding of the government in power. We address this issue with support in bibliographic and documentary studies, dialoguing with authors such as Abio (2016); Sedycias (2005); Picanço (2003), Gonzales (2008) and Fernández (2005) and reflecting on laws, resolutions, decrees, technical guidelines and other official documents of the Brazilian Ministry of Education and Culture. We take as a starting point a panorama of legislation that begins in 1942 and reaches 2020 and we address the intersection between teaching and teacher training, presenting benefits and harms that in fact call for reflection and search for solutions that give stability to this knowledge that results in a benefit for society as a whole, since tourist, social and economic aspects represent space for the growth of the country and the fulfillment of lives. We conclude that the instability regarding the presence of the Spanish language in the Brazilian educational system notoriously harms society and does not seem to be a weighty knowledge at certain times; Furthermore, the lack of official documents containing arguments that justify the high historical oscillation that the teaching of Spanish has always presented is perceptible.

Key Words: Going and turning, Uncertainty, Spanish Language Teaching, Teacher training.

\section{INTRODUCCIÓN}

Resulta difícil comprender la facilidad con que las personas admitimos en un momento y en otro ignoramos el lugar y la importancia que una lengua extranjera como el español, ha tenido, tiene y tendrá siempre en las sociedades más diversas del mundo, principalmente en el continente americano. La pregunta que salta es ¿por qué la lengua española es más o menos 
importante para el brasileño en un determinado tiempo y en otro no?

En este trabajo, nos proponemos reflexionar sobre la severa implicancia que el histórico de idas y vueltas de la lengua española a la oficialidad/legalidad/obligatoriedad de su enseñanza ha tenido a través de todos los tiempos en que esta haya estado involucrada, sobre todo desde 1942. La obligatoriedad de su enseñanza terminó afectando, de inicio, positivamente, pues se valoraron razones geográficas e económicas que incumbían a Brasil; pero más tarde, el efecto negativo se vio claro cuando se le dio la espalda y se le retiró de la obligatoriedad, pareciendo que Brasil se mudó físicamente y pasó a no relacionarse más con países hispanohablantes. El "quita y pon” que nos llega hasta la actualidad, bambolea su enseñanza, la formación de profesionales y la real posibilidad de acercarse a una lengua, conocerla y dominarla; hasta parece que ese tema fuera al ritmo y entendimiento del gobierno de turno.

Por lo dicho, abordamos este tema con respaldo en estudios bibliográficos y documentales, tomando como punto de partida un panorama de legislaciones que inicia en 1942 y se muestra hasta el presente año de 2020 con cambios bastante acentuados y llenos de nuevos documentos nacionales para la educación que también tocan la enseñanza de lengua española.

Es perceptible que la creciente incertidumbre de la valoración que se proyecta a partir de la obligatoriedad o no de la lengua española, afecta, a los días de hoy, no solo al aprendizaje de la lengua y la formación del profesorado para su enseñanza, sino a las varias posibilidades que la sociedad tendría a su alcance en el desempeño de sus labores con mejor calidad en su perfil profesional, en sus alcances comerciales más allá de los límites de Brasil. El perjuicio también se da para los estados con potencial turístico, comercial y cultural, al no contar con mejor estructura para recibir al turista extranjero, pues español es la $2^{\mathrm{a}}$ lengua más hablada, después del chino mandarín y el $2^{\circ}$ idioma de comunicación internacional, ¿cómo no estudiarla formalmente en Brasil?

De 2005 con la ley $n^{\circ} 11.161$ (ley del español) a 2016 con su respectiva derogación, la inestabilidad se ha instalado para aquellos que se graduaron o aún se venían graduando para la docencia de lengua española; sin escuelas o instituciones que la contemplen en sus currículos escolares y/o académicos, ¿en qué trabajarían los profesores egresos de español?, ¿dónde quedaría el tema de la vocación docente de lengua española? ¿cómo contribuir en la formación de personas de áreas como el turismo, el comercio, la banca?, etc., etc.

Creemos que tener en cuenta el histórico en Brasil de la enseñanza formal, oficial u obligatoria de la lengua española en la educación básica lleva a configurar la inestabilidad de su presencia en los currículos escolares y, por ende, en la formación de los profesores para enseñarla, así mismo lleva incluso a poner en duda su importancia. 
Lo que más ha inquietado y llevado a escribir sobre este asunto es la clara ausencia de razones para la oscilación en la obligatoriedad de la enseñanza de español en Brasil, eso se ha tornado una fuerte razón que justifica nuestro estudio y nos encoraja a explorar más, sobre todo por los hechos más recientes y los fuertes cambios para la educación, en específico para la enseñanza de lengua española.

Se consigue ver este trabajo como un elemento que contribuye a la comprensión histórica, en su diacronía y sincronía, respecto al tratamiento dado a la lengua española en la enseñanza formal en Brasil y que hoy no está beneficiando al estudiantado, ni al ciudadano que define su vida profesional en esa área, ni al ciudadano que requiere de personas y espacios donde cultivar esta lengua, que desde nuestra consideración, es posible conocerla razonablemente para todas las finalidades que el mundo actual exige aún en la enseñanza básica, el perjuicio es para la sociedad como un todo.

\section{FUNDAMENTACIÓN TEÓRICA}

Es importante y pertinente hablar sobre la enseñanza de español en Brasil, así como analizar las legislaciones que tratan de este asunto, pues ya se han ido, no solo años, sino también esperanzas e ilusiones de ver que la lengua española sea llevada a serio, debido a tantas idas y vueltas, que la verdad, ya se tiende a pensar que esta oscilación en su relevancia para el país y el mundo es vista dentro de lo esperado. Pero, aun así, traemos datos concretos y recientes del informe 2020 del Instituto Cervantes (2020, pág.12) por los que:

Se estima que, en 2020, más de 22 millones de alumnos estudian español como lengua extranjera; en concreto, 22.329.275. Este es el resultado de sumar el número de estudiantes de español existentes en la actualidad en 110 países. Las cifras se refieren a todos los niveles de enseñanza - incluida la no reglada - y se ciñen a los datos disponibles en cada uno de los países. Con todo, la ausencia de datos universales, completos y comparables confiere un carácter provisional a los cálculos, ya que, por ejemplo, apenas reflejan información de los centros de enseñanza privada. Por ello, se estima que hay un número de alumnos de español aún no contabilizados que podría rondar los cinco millones.

O sea, en pleno 2020, al todo y de forma aproximada, se puede decir que son 27 millones de personas que estudian español, cifra importante que debería ser tomada en cuenta por nuestros gestores educacionales a la hora de reglamentar la enseñanza formal de una lengua extranjera en el país. Además, González (2008, pág. 3177-3178), presentó algunas razones para validar la obligatoriedad del español en Brasil con respecto a la realidad de América Latina:

La obligatoriedad del español - una lengua que por muchas veces y distintas 
razones ya ha estado presente en las escuelas brasileñas - fue y es defendida y sostenida en función de necesidades de integración con naciones vecinas y hermanas, con fuerte énfasis para su papel en el Mercosur. [...] .

Entendemos que, en la actualidad, estas razones no han tenido peso suficiente para mantener la enseñanza curricular en Brasil, pues en 2016 fue vetada su presencia en el currículo del estudiante de educación básica.

Pero vamos por partes, en este artículo verificamos la Ley de Directrices y Bases de la Educación - LDB de 1996, la Ley 11.161 de 2005, la MP 746 de 2016, la Ley 13.415 de 2017 y aún la Base Nacional Comum Curricular - BNCC con la intención de rememorar la trayectoria de la lengua española como oficial o no, en la educación brasileña. Además, dialogaremos con autores que abordan este tema como: ABIO (2016), SEDYCIAS (2005), PICANÇO (2003), GONZÁLEZ (2008) y FERNÁNDEZ (2005) quienes nos darán contribuciones importantes.

Inicialmente necesitamos reflexionar sobre la importancia de la lengua española para el pueblo brasileño, pues es muy común que se justifique la enseñanza del español en Brasil por el hecho de establecer fronteras con siete países cuyo idioma oficial es el español (Uruguay, Argentina, Paraguay, Bolivia, Perú, Colombia y Venezuela). De esa forma, el acercamiento geográfico y entre las lenguas hace que uno "se sienta en la cultura en español como algo afín [...] y fomenta la actitud favorable de los brasileños hacia la cultura hispana" (MORENO FERNÁNDEZ, 2005, p. 21).

Según Moreno Fernández (2005, p. 17), los primeros registros de la lengua española en Brasil figuran en los viajes exploratorios de Colón por la costa sudamericana (1494 y 1495) con el objetivo de demarcar el área establecida por el Tratado de Tordesillas. Fueron 424 años los que pasaron para implementarse la enseñanza del español en el sistema educativo nacional (1919), en la prestigiada institución pública, el Colegio Pedro II, en Río de Janeiro, en carácter de asignatura optativa, bajo la responsabilidad del profesor Antenor Nascentes. El referido docente fue autor, entre otras obras, de la Gramática da Lengua Española, publicada en 1920.

Aún conforme Moreno Fernández (2005), uno de los hechos más expresivos para la difusión del idioma fue el flujo migratorio de españoles que se dio por la crisis económica de la mitad del siglo XIX cuando gran parte de los inmigrantes buscó el sur y el sureste de Brasil en el siglo siguiente. São Paulo, por ejemplo, llegó a reunir al 75\% de los trabajadores inmigrantes españoles que estaban en el país.

Con tantos españoles en territorio brasileño la lengua empezó a ganar notoriedad entre los ciudadanos, haciendo con que las legislaciones educacionales pensasen sobre esta lengua, reflejando su importancia. En toda la historia de la educación brasileña fueron efectuadas varias 
reformas en el sistema educativo con la intención de proponer la inclusión del español como LE - Lengua Extranjera desde 1942 hasta la sanción de la Ley 11.161/2005 por el presidente de la República Luiz Inácio Lula da Silva, que instituyó la oferta obligatoria de la Lengua Española en los currículos plenos de la Enseñanza Media y de carácter facultativo en la Enseñanza Fundamental. Esta ley representó un gran marco en lo que concierne el estudio y enseñanza de español en Brasil, quizás sea el principal documento que refleje la consideración de conocimiento importante para los brasileños.

Como habíamos dicho, en 1942 surgió la primera legislación educacional que incluyó la lengua española como asignatura obligatoria, con la intención de crear un conjunto de medidas para la reestructuración de la educación nacional dando mayor relevancia a las lenguas clásicas y modernas, con eso, la lengua española fue incluida por primera vez en la Enseñanza Media como una opción de enseñanza de lengua extranjera que marcaba inglés en el ciclo "ginasial" y una lengua extranjera no especificada en el ciclo colegial.

Figura 02: Publicación Oficial en el "Diario do Congresso Nacional de 13 de novembro de 1948.

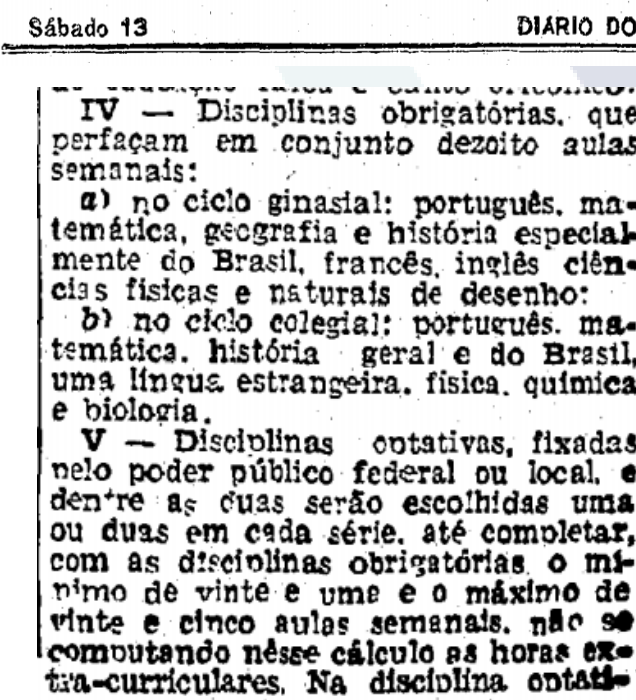

\section{Sábado 13}

Novembro de $1948 \quad 11619$

Fonte: Título VII, Capítulo III.

Disponível em: http://imagem.camara.gov.br/Imagem/d/pdf/DCD13NOV1948.pdf

En 1961, surge la primera versión de la Ley de Directrices y Bases de la Educación LDB y en su contenido retira la obligatoriedad de la enseñanza de lengua Extranjera y deja que los Consejos Estatales de Educación hagan la opción por la inclusión en los currículos. Se puede considerar este, como el primero gran retroceso dentro de este proceso de implementación de la enseñanza de español en Brasil. Con este paso atrás, queda muy claro, que la lengua española todavía no detiene prestigio pues, primeramente, pasó a ser obligatoria con carga horaria 
mínima, caracterizando irrelevancia. Después, retiran su obligatoriedad dejando a cargo del criterio de los Estados.

En el año 1996 es publicada una nueva versión de la LDB - Ley de Directrices y Bases de la Educación, que hasta hace poco reglamentaba la enseñanza en las escuelas brasileñas. Esta nueva versión determinó que la enseñanza de lenguas fuese obligatoria a partir de la $5^{\text {a }}$ serie, abriendo caminos para que las lenguas extranjeras pudiesen seguir siendo enseñadas en las escuelas. O sea, con esa determinación, retomamos lo que había sido definido en 1942. Pero, tenemos que resaltar:

[...] na parte diversificada do currículo será incluído, obrigatoriamente, a partir da quinta série, o ensino de pelo menos uma língua estrangeira moderna, cuja escolha ficará a cargo da comunidade escolar, dentro das possibilidades da instituição (BRASIL, 1996 Art, § 5º.

La LDB no deja claro qué lenguas extranjeras modernas son estas que las escuelas deberían ofertar, en ningún momento habla específicamente sobre la enseñanza de español. Según SEDYCIAS (2005, p. 24) a LDB no especifica un determinado idioma extranjero a ser estudiado y afirma que la existencia de países hispanohablantes alrededor de Brasil no es motivo suficiente para establecer una legislación favorable al español.

La impresión que ha quedado latente siempre ha sido de que el sistema público brasileño en la figura de sus gestores educacionales y directores escolares no han demostrado interés en el tema de la enseñanza de español, probablemente porque no comprendieran el valor de ese conocimiento para la realidad de la sociedad brasilera.

En los años 90 surge una idea de valoración y defensa de la enseñanza de español en Brasil. Aspectos como la llegada de diversas empresas e instituciones españolas en Brasil y el propio peso de la cultura española y su influencia, contribuyen para que haya interés en esta lengua destacándose la expansión de las relaciones comerciales entre Brasil y países latinoamericanos. Por otro lado, la formación de profesores de español era escasa, pocas universidades ofertaban el curso, pues la vocación profesor de español se oprimía en la visión de un mercado de trabajo vacío, sin espacio.

No obstante, e a partir de entonces, la enseñanza de español comienza a ser vista de otra forma, muchas conquistas ocurren desde la LDB, observándose una mejora contundente con la promulgación de la Ley 11.161, de 05 de agosto de 2005. Esta ley es lo mejor que se ha podido vivir a este respecto. Activó un tránsito fluido de formación de profesores, espacio en el mercado de trabajo con oportunidades impares de vacante para el servicio docente público, acelero la producción y elaboración de materiales didácticos, acentuó el intercambio con países 
hispanohablantes, en especial España que siempre ha estado y continua estando presente a través de su Ministerio de Educación y su Embajada en Brasil.

La obligatoriedad de la conocida ley del español, Ley 11.161/2005, se centró en la oferta por parte de las escuelas, siendo opción del estudiante cursarla o no, tal como vemos en el artículo $1^{\circ}$ de la referida ley ${ }^{3}$ :

Art. $1^{\circ} \mathrm{O}$ ensino da língua espanhola, de oferta obrigatória pela escola e de matrícula facultativa para o aluno, será implantado, gradativamente, nos currículos plenos do ensino médio.

$\S 1^{\circ} \mathrm{O}$ processo de implantação deverá estar concluído no prazo de cinco anos, a partir da implantação desta Lei.

$\S 2^{\circ}$ É facultada a inclusão da língua espanhola nos currículos plenos do ensino fundamental de $5^{\mathrm{a}}$ a $8^{\mathrm{a}}$ séries.

Esta realidad conllevó a una serie de situaciones, fueron notadas discusiones respecto a algunas incoherencias e incluso subjetividad. La percepción del trato diferenciado para instituciones públicas y privadas dando condiciones distintas cuanto a la implantación, obviamente provocó malestar para los profesores involucrados.

Art. $2^{\circ} \mathrm{A}$ oferta da língua espanhola pelas redes públicas de ensino deverá ser feita no horário regular de aula dos alunos.

Art. $3^{\circ}$ Os sistemas públicos de ensino implantarão Centros de Ensino de Língua Estrangeira, cuja programação incluirá, necessariamente, a oferta de língua espanhola.

Art. $4^{\circ}$ A rede privada poderá tornar disponível esta oferta por meio de diferentes estratégias que incluam desde aulas convencionais no horário normal dos alunos até a matrícula em cursos e Centro de Estudos de Língua Moderna.

Aún con todo, fue sí una victoria importante, finalmente se tendría la clara posibilidad legislada de enseñar y aprender español en las escuelas. Se trataba de una ley exclusiva para legislar la enseñanza de lengua española en la educación básica brasilera con el consecuente y subsiguiente movimiento proficuo en la formación de nivel superior de profesores para atender esta ley, que a título de muestra, en el estado do Rio Grande do Norte, sería necesario contar con 279 profesores de español para la escuela pública que no había y fue entonces necesario implementar, ampliar la oferta de formación de profesores de español en las instituciones de enseñanza superior. (CACHERO LASECA, 2008, PAG.205).

Hubo toda una formulación en un periodo de 5 años que generó cursos, concursos, nuevas escuelas especializadas y demás, pero no duró mucho. En 2016 fue publicada la Medida Provisoria 746, cuyo contenido trataba de una propuesta de alteraciones en la estructura de la

3 Disponible em: https://www.planalto.gov.br/ccivil 03/ ato2004-2006/2005/lei/l11161.htm Visto el 20/08/2020. 
enseñanza media, una de esas propuestas era anular la ley del español. Hecha la consulta pública por el gobierno federal, se verificó y demostró que las personas no eran favorables a lo que estaba siendo propuesto, ya que 73.554 personas dijeron NO y sólo 4.551 dijeron SÍ al contenido de la MP, sin embargo, la Medida Provisoria se convirtió en contenido de la ley 13.415 de 2017.

Y así, una vez más la enseñanza de español fue colocada ante un representativo escenario de retroceso. Fueron doce años dedicados y avocados por completo a este conocimiento que impactaron negativamente la vida de muchos y muchos ciudadanos brasileros.Un ejemplo es el discurso representativo de la vicepresidente de la Asociación de Profesores de Español de Alagoas:

A vice-presidente da Associação de Professores de Espanhol do Estado de
Alagoas (APEEAL), a professora Eronilma Barbosa, em entrevista à Rádio
Maceió, informou que os professores e alunos estão lutando para que a
disciplina volte ao currículo escolar do ensino médio. De acordo com a
professora, no dia 17 de fevereiro de 2017 foi sancionada a Lei 13.415, que
revogou a Lei do Espanhol, Lei 11.161 , de 05 de agosto de 2005, sancionada
pelo Presidente Lula e que favoreceu o ensino da língua espanhola em
Alagoas, no Brasil. "O ensino da língua espanhola no estado de Alagoas é de
extrema importância, assim como em todo o Nordeste. Dados oficiais da
Secretaria de Turismo do Estado de Alagoas mostram que $66 \%$ dos turistas
que chegam ao estado são de origem Hispânica, ou seja, falam Espanhol como
língua materna". A vice-presidente da APEEAL destaca ainda que o problema
não afeta apenas os professores e alunos do ensino médio. "Afeta as
universidades, o curso de Letras. Para que formar professores de Espanhol se
estão tirando da grade curricular. Além disso, outro dado importante é que
$71 \%$ dos alunos que se preparam para o Exame Nacional do Ensino Médio
(Enem) no Nordeste escolhem o Espanhol como língua estrangeira. Retirando
o Espanhol do ensino médio, estamos retirando a porta de entrada dos alunos
da escola pública para a universidade". (GAZETAWEB, 2020)

Como se puede ver, fueron levantadas cuestiones muy importantes, reflexiones que hasta el día de hoy no tienen respuesta aún. Fue una decisión tomada por el gobierno sin que mediara diálogo con la sociedad, sin que hubiera una justificativa para tal mudanza, tan radical como lo fue el momento nacional que se vivía na convulsión de un “impeachment presidencial”. Hasta hoy, la sociedad brasilera no ha tenido respuesta que justifique ese drástico cambio, algo que mensuramos como lamentable y gran punto de retorno al retroceso impuesto por un gobierno nuevo que no percibe la importancia del idioma español para la educación del pueblo brasileño.

La Ley 13.415 de 2017 impone diversos cambios en la grade curricular de la Enseñanza Media, proponiendo una reformulación efectiva. Lino (2017, pág. 77) retrata muy bien y de manera crítica lo que representa la derogación de la Ley. 


\begin{abstract}
A MP 746/2016, doravante citada como Lei 13.415/2017, imposta de forma autoritária e unilateral, confirma a postura do Executivo de desconsiderar a pluralidade de concepções acerca do ensino médio e se negar ao diálogo com os profissionais da educação e suas entidades representativas, bem como com os estudantes, público-alvo da ação, sem esquecer do descaso com as instituições formadoras e entidades científicas, que poderiam contribuir no complexo processo que uma 'reforma' requer.
\end{abstract}

No se puede negar que esta ley es arbitraria y que no tiene cualquier fundamento técnico capaz de justificar lo que impone. Ella hiere un derecho conquistado y coloca en retroceso la educación brasileña. No debería haberse tratado de "quitar" y sí de agregar, en este caso, la obligatoriedad de la lengua inglesa.

\title{
METODOLOGIA
}

El presente estudio es de carácter exploratorio, una investigación básicamente bibliográfica estableciendo diálogo con autores como Abio (2016); Sedycias (2005); Picanço (2003), Gonzales (2008) e Fernández (2005) abarcando estudio documental revisando documentos oficiales del Gobierno Federal, más exactamente del Ministerio de Educación y Cultura de Brasil. Nuestro campo de investigación es la legislación brasilera en el ámbito de la enseñanza de lengua española y de la formación de profesores de español.

\section{RESULTADOS Y DISCUSIONES}

Según las OCEM (BRASIL, 2006, p. 128), a pesar de estar rodeados de países cuya lengua oficial es el español, hay prejuicios, y el sentido común disemina, entre otras ideas, que el español es una "lengua fácil", accesible, posible alcanzar. Se reflexionó acerca de ideas de ese tipo cuando hubo demandas para satisfacer el ámbito económico, debido a la creación del Mercosur y de las consecuentes relaciones de negocios con España, pero creemos que lo importante no se contempló y nos referimos a la accesibilidad del brasileño para comunicarse en una lengua extranjera con dominio y soltura, algo que difícilmente se alcanza al tratarse de otra lengua. Consideremos el comentario hecho en el informe "O ensino de inglês na educação pública brasileira":

[..] 59\% dos professores sentem que o ensino do inglês é desvalorizado ou é distante da realidade dos alunos. Para eles, a vulnerabilidade social dos alunos muitas vezes faz com que estes não percebam como o ensino de inglês pode ser relevante para a sua formação. [...] (2015, pág. 18) 
Sí, creemos que es desvalorizada la enseñanza de lengua extranjera en la escuela pública y no solo del inglés, sino de cualquier otra que se pueda implementar, pues lo más, es la realidad de los estudiantes, la vulnerabilidad y la distancia que se interpone entre encontrar sentido y desear aprender y el poder aplicar ese saber de forma relevante, con significado.

En segundo punto, considerando que las lenguas de mayor relevancia para el mundo de la formación, sea básica, media o superior, para el mundo del trabajo y de la información en Brasil, son, en general, inglés, español y francés, creemos que todo tomaría otra dimensión si se aceptara realidades cuanto al logro de metas de aprendizaje y efectiva aplicabilidad a la vida del ciudadano.

Nos inclinamos fuertemente a pensar que determinados aspectos y estatus son cruciales para la toma de decisiones por parte de la gestión educacional brasileña para determinar qué lengua sería realmente un "plus" para la formación básica y qué otra para la vida profesional. Implicaría decir que la enseñanza de una lengua para la educación básica: 1) transparente que estimule el gusto de sentir avance en el aprendizaje, al punto de buscar, incluso, hacerlo de forma autodidáctica; 2) pronunciable, accesible en su pronunciación por tener los sonidos como parcialmente conocidos y del mismo origen (neolatinos); y 3) destacada en el ambiente mundial de la comunicación, ocupando un segundo lugar como lengua de comunicación internacional. Esa lengua sería el español, de hecho, la lengua que tendría más sentido implementar como componente formal en la educación básica.

Por otro lado, es innegable la importancia actual de la lengua inglesa, pero no para la realidad brasileña de la enseñanza básica, y sí la vemos como la lengua de acertada opción para las personas que ven clara la necesidad y el posible uso y aplicación profesional. Para la formación fundamental y media, a través del tiempo y vivencias, vemos que es infructífera, que la vulnerabilidad de los estudiantes de la escuela pública en Brasil habla más alto y no permitirá echar mano de avances por no tener practicidad y sentido para este segmento de la sociedad.

A todo esto, es importante hablar del papel que una lengua extranjera juega en la educación básica de un brasileño pensado por los profesores, cuál sería esa función. Para tal, traemos la figura 02 que muestra un gráfico de porcentajes de los papeles o funciones que representa aprender inglés, aludidos por los profesores entrevistados en ese estudio, procederemos a analizar básicamente los 3 papeles o funciones señaladas con el mayor porcentaje, contrastando la información con la realidad o configuración que tendría la lengua española para los brasileños: 
Figura 02: Ausencia de papel claro en la formación de alumnos - Función del inglés para el alumno, según la visión de los profesores.

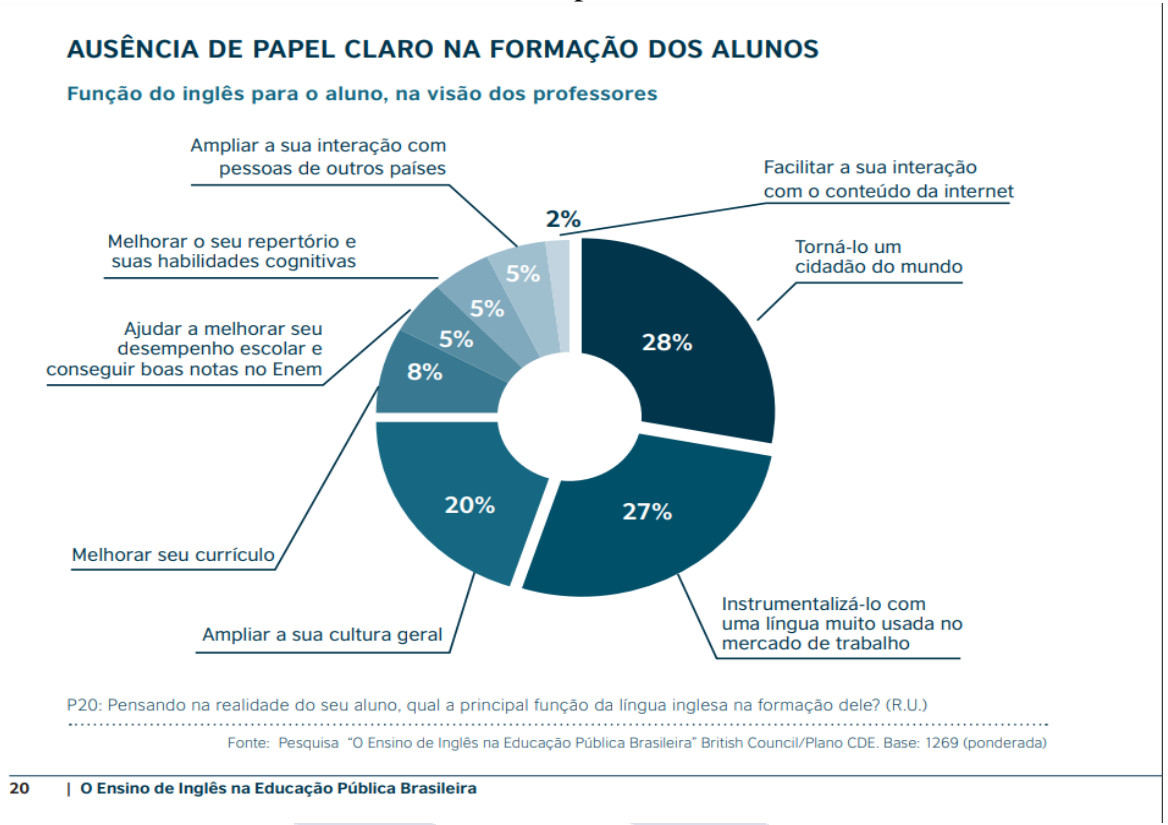

Fuente: Adaptado de “O ensino de inglês na Educação Pública Brasileira”. $1^{\text {a }}$ Ed. São Paulo, 2015, pág. 20 .

$\checkmark 28 \%$ de los profesores entrevistados afirmaron que la lengua inglesa tenía el papel o función de TORNAR AL ESTUDIANTE UN CIUDADANO DEL MUNDO: Para que esta función tenga cabida, creemos que sería necesaria la existencia de un programa pleno y plano de intercambio para los estudiantes de educación básica de la escuela pública. Sabemos que esa realidad mal se concreta para los estudiantes de escuelas privadas y difícilmente se consigue para los de educación superior. Tornar a alguien ciudadano del mundo implica en hacerlo vivir culturas, conocer gentes, abrazar costumbres, conseguir eso en el contexto de la lengua inglesa es demasiado ambicioso y corre ciertos riesgos de quedar en palabras o intenciones. Pero, la proximidad geográfica y la circulación de hispanohablantes en Brasil, sí podría proporcionar este papel o función, si se tratara de la lengua española, claro;

$\checkmark 27 \%$ INSTRUMENTALIZARLO CON UNA LENGUA MUY USADA EN EL MERCADO DE TRABAJO: Un estudiante de educación básica de escuela pública difícilmente alcanzaría un nivel razonable de lengua inglesa al punto de permitirle conseguir un empleo, quizás pudiera ser si tuviera la oportunidad de un proceso de inmersión o entrega importante para el estudio y sobre todo la práctica de la lengua inglesa, pero lo que sí, es muy probable que de lengua española sí consiga, está más próxima de su realidad lingüística y podría aplicarlos en ámbitos como el turismo, la 
artesanía, las ventas, etc., puede encontrar espacio para trabajar.

$\checkmark 20 \%$ AMPLIAR SU CULTURA GENERAL: También puede realizarse este aprendizaje en otras lenguas, por supuesto, el español también.

Por lo dicho, ofrecer a un estudiante brasileño la posibilidad de conocer, dominar y prepararse para el mundo del trabajo con una lengua extranjera como el español, pensamos que es válido porque cuenta con una armonización mucho más acentuada que si se tratara de la lengua inglesa o francesa, que, se quiera o no, son lenguas un poco ajenas del cotidiano de un estudiante de educación básica y pública.

Gonzalo Abio (2016) hace algunas contribuciones relevantes cuando dice que necesitamos reconocer que la situación del español nunca fue buena en la práctica real y nosotras desde nuestra experiencia docente podríamos decir que incluso empieza a asemejarse a la realidad de la enseñanza de inglés en la escuela pública. Abio (2016) complementa diciendo que:

Nos últimos anos os gestores de educação municipais quase extinguiram o ensino de espanhol no segundo segmento do ensino fundamental (sexto a nono ano escolar). Por outro lado, a situação no ensino médio é bastante variável, mas salvo casos pontuais, o trabalho com a língua espanhola também deixa bastante a desejar. Não por culpa dos professores, mas sim por causa "do sistema" que não contrata professores suficientes, não investe em formação e não estimula um ensino regular da língua nos três anos do ensino médio.

El sistema educacional público, principalmente el estatal, respecto de la enseñanza de lengua extranjera en Brasil de hecho falla, empezando por la visión "realística" del destinatario de esa enseñanza, estudiantes en su mayoría de escasos recursos, de contextos de vida muy difíciles que los lleva, veladamente, a creer que con una lengua extranjera no va a impactar a más en esos estudiantes. Lo que es inexplicable e inaceptable, no se justifica creer, es fundamental propiciar la oportunidad. Debería cumplirse lo que la propia Constitución de la República Federativa de Brasil, como marco legal apunta educación y derechos.

Además, en su Título 1, “Dos princípios fundamentais”, Artículo 4, párrafo único, se determina que: "A República Federativa do Brasil buscará a integração econômica, política, social e cultural dos povos da América Latina, visando à formação de uma comunidade latinoamericana de nações" (1988, p. 11). Así dice el documento máximo del país, una regla que respalda el argumento de la adopción de una política lingüística que sea adecuada y cercana a la región considerando realidades locales y procesos compartidos con las naciones latinoamericanas.

La afirmación que Gonzalo Abio (2016) hace sobre la enseñanza de las lenguas 
adicionales en las escuelas en el sentido de no haber tenido hasta ahora un lugar de importancia, nos lleva a observar diversos motivos, entre ellos la falta de políticas públicas por parte de cada provincia; la falta de explicitación en los documentos legales al respecto de las lenguas extranjeras, los orientaciones, por lo general, son generalistas y dejadas las decisiones de implementación en manos de directores, que según su entendimiento, valoración y posibilidades irán a implementar o no la enseñanza de lengua extranjera, sea inglés, sea español o la que sea, muchas veces sin una noción de mundo en ese ámbito, saber que quizás los profesores tengan, pero es un saber solitario, un saber que difícilmente es atendido o escuchado. La realidad de la escuela pública impera, sin más.

As carências no ensino de línguas na educação básica ficaram evidenciadas com a chegada do Programa Ciência sem Fronteiras e a necessidade urgente de tentar encontrar vias para potenciar o ensino de línguas e a proficiência mínima necessária dos bolsistas desse programa que em grande número viajaram para o exterior. Alguns projetos estaduais e nacionais foram estabelecidos e brindaram seus resultados para contornar a situação, mas não tiveram a abrangência e profundidade para mudar o quadro nacional calamitoso de desrespeito com as línguas estrangeiras na educação básica. (ABIO, 2016)

Ante el panorama histórico y las cuestiones de organización nacional que lleven a programas de calidad para la enseñanza de lengua extranjera en la educación básica reglada en Brasil, creemos que va a llevar un buen tiempo asimilar el importante papel que la enseñanza de lenguas extranjeras desempeña en la formación holística del ciudadano y el papel que la lengua española juega de forma directa en Brasil.

Por otro lado, las idas y vueltas en la formación de profesores para la enseñanza de lenguas extranjeras es un importante tema a rememorar y también del que reflexionar, pues está enganchado estrecha y permanentemente al quehacer educacional.

Hasta antes de la Ley del Español ${ }^{4}$, la formación de profesores de lengua española ocurría en muy pocas universidades del país, concentradas principalmente en el sur y en el sudeste, pero en el estado de Rio Grande do Norte, solo la UERN (Universidad Estadual do RN) formaba en lengua española, quizás hayan sido los primeros profesores de español de este Estado en un momento de insipiente mercado de trabajo, pero de mucha vocación y amor para dedicarse a una formación que no rendiría un empleo razonable, por ejemplo.

En el tiempo posterior a la ley del español, hubo la necesidad de crear cursos superiores de formación de profesores de lengua española, pues había pocos, muy pocos, y se buscaba que

\footnotetext{
${ }^{4}$ Ley no11.161 de 2005.
} 
hubiera consonancia entre demanda y oferta docente con el nuevo estatus del español como asignatura de oferta obligatoria, hacía falta muchos profesores para cumplir la ley.

Hasta llegar a ponerse en vigor el actual documento para la enseñanza pública, llamado BNCC (Base Nacional Común Curricular), el marco legal de la formación de profesores también pasó de forma indirecta por la Constituição Federal de 1988, en la que se plasma el reconocimiento del derecho a la educación como fundamental y compartido entre el Estado, la familia y la sociedad; la legislación que regía la formación de profesores iba acompañando de acuerdo con la Ley de Directrices y Bases (LDB) de 1996, las Directrices curriculares elaboradas por el Conselho Nacional de Educação (CNE) del año 2000, luego su readecuación en 2010, hasta llegar al Plan Nacional de la Educación (PNE) en 2014 en el que se asevera la importancia de una base nacional común curricular para Brasil.

La formación de profesores fue acompañando y adecuando el currículo, obedeciendo el marco legal que demandaba la educación básica, no obstante, en el periodo entre 2005 y 2016, había una corriente fuerte en lo que se refería a la formación de profesores de lengua española, la demanda de docentes tenía alta expresión en edictos de concursos públicos y oferta en escuelas particulares. El flujo de formación era acentuado, más personas buscaban graduarse para la docencia de español, las escuelas del Estado y del Municipio tenían por lo menos 01 docente por escuela, circulaba un flujo importante de eventos académicos y el país enteró se movía para participar, con eso todos ganaban.

Un buen día, en medio a ninguna justificativa surge una medida provisoria del Gobierno, en 2016, que retiraba la obligatoriedad de oferta de lengua española en la enseñanza pública que al año siguiente se constituyó en la ley nº13.415 del 16 de febrero de 2017 en la que se deroga la Ley del Español; con eso, estudiantes en formación, formados, estudiantes de enseñanza básica y muchos más quedaron perplejos, sin comprender siquiera la principal razón de haber retirar el funcionamiento de una mega estructura construida durante una década para que la sociedad accediera a la posibilidad de hablar una lengua que tendría más sentido que cualquier otra para sí durante la educación básica.

Aun así, sin la existencia de ese mecanismo legal para propiciar el acceso a ese conocimiento en las escuelas públicas, se continuó formando profesores de español en las instituciones que crearon el curso para atender la ley. Las escuelas estatales y municipales, en buena parte, entendieron que solo se debería enseñar lengua inglesa y retiraron el español del currículo escolar, a pesar de contar con un docente graduado en español que terminaba en la biblioteca, en el sector administrativo o cualquier otro y no actuando profesionalmente para lo que se formó y fue concursado, esa realidad es parcial, pero existe, lo que causa impotencia. 


\section{HISTÓRICO DE IDAS Y VUELTAS EN LA ENSEÑANZA DE ESPAÑOL ...}

Por otro lado, los estudiantes de graduación en formación, al ver que su mundo profesional desaparecía, no existiendo más un mercado de trabajo seguro donde laborar, cómo crecer profesionalmente, cómo permanecer estudiando 1, 2 o 3 años más sin una clara perspectiva, todo eso y más, generó desánimo, impotencia y abandono de estudios, un trágico fin para un saber relevante para la realidad social de Brasil.

\section{CONCLUSIONES}

El amparo legal para la enseñanza de lengua española en Brasil, de hecho, está marcado por un histórico de idas y vueltas que ha tendido a acentuar la desvalorización de esta lengua y su importancia para la educación básica pública, no habiéndose conseguido encontrar en ninguno de los documentos leídos posibles justificativas por haber sido preterida o retirada de la obligatoriedad sea de oferta o de enseñanza en varios momentos de la historia.

Reflexionamos seriamente sobre las afirmativas encontradas que justifican su inclusión como conocimiento relevante para la educación brasilera, pero que no contaron a la hora de excluirlo, a saber, razones geográficas, económicas y comerciales que siempre han sido y continúan siendo verdaderas al tratarse de la lengua española.

Creemos que para la realidad brasileña de la educación básica, la lengua que tendría más aprovechamiento en su aprendizaje y formación, sería de hecho la lengua española, debido a: 1) su transparencia lingüística si comparada con el portugués brasileño; 2) a su posibilidad de acentuada aproximación a la pronunciación de los sonidos del español; 3) a su realidad social y cultural, por tener posibilidades reales de contacto y; 4) sobre todo, al perceptible estímulo de mirar hacia posibilidades de empleo a corto plazo en ramos como el comercio, el turismo, la artesanía y similares, sin un estudio particular y especializado en simultáneo.

Encontramos en la bibliografía consultada afirmaciones en el sentido de que la lengua española está históricamente marcada por una inestabilidad que se refleja en las varias ocasiones en que se le tornó obligatoria y luego, sin más, fue retirada ocasionando serios perjuicios a todos que de alguna forma se encuentren involucrados. Los estudiantes, perjudicados porque se les impone una lengua que para su momento de vida y realidad social carece de un significado y una función o papel preponderante. Los estudiantes de graduación y graduados, porque invierten tiempo, esfuerzo y dedicación preparándose para desempeñar la docencia de lengua española y de repente desaparece el futuro que visualizó y en el que apostó.

\section{REFERÊNCIAS}

ABIO, Gonzalo: A MP 746 e o futuro do ensino de espanhol no Brasil. Disponível em: 
http://gonzaloabio-ele.blogspot.com.br/2016/09/a-mp-e-o-futuro-do-ensino-de-espanhol.html. Acessado em: 22/08/2020.

BRASIL. Constituição da República Federativa do Brasil, de 05 de outubro de 1988.

BRASIL. Lei de Diretrizes e Bases da Educação: Lei nº 9.394/96 - 24 de dez. 1996. Disponível em: http://portal.mec.gov.br/seed/arquivos/pdf/tvescola/leis/lein9394.pdf. Acessado em: 12/09/2020

BRASIL. Medida Provisória 746, de 22 de setembro de 2016. Diário Oficial [da República Federativa do Brasil], Brasília, DF, 23 de setembro de 2016, Seção I, p.1. Acessado em: $12 / 09 / 2020$

BRASIL. Presidência da República, Lei n 11.161, de 05 de Agosto de 2005. Disponível em: http://www.planalto.gov.br/ccivil_03/_Ato2004-2006/2005/Lei/ L11161.htm. Acesso em: 14/08/2020.

BRASIL. Orientações Curriculares para o Ensino Médio: Linguagens, Códigos e suas Tecnologias. Brasília, Secretaria de Educação Básica, 2006.

BRASIL. Lei de Diretrizes e Bases da Educação Nacional. Lei nº 13.415/2017, de 13 de fevereiro de 2017. Disponível em: <http://www.planalto.gov.br/ccivil_03/_ato20152018/2017/lei/L13415.htm>. Acesso em: 03/09/2020.

BRASIL. Câmara dos Deputados, Lei no 4.024 de 20 de dezembro de 1961. Disponível em: https://www2.camara.leg.br/legin/fed/lei/1960-1969/lei-4024-20-dezembro-1961-353722publicacaooriginal-1-pl.html . Acesso em: 14/08/2020.

CACHERO LASECA, Álvaro M. La enseñanza del español en el sistema educativo brasileño. Colección Orellana nº19. Edición bilingüe. Consejería de Educación. Embajada de España en Brasil. Brasilia: 2008.

CERVANTES, INSTITUTO. El español: Una lengua viva. Informe 2020. Edición digital NIPO: 110-20-018-0. Disponível em:

https://cvc.cervantes.es/lengua/espanol_lengua_viva/pdf/espanol_lengua_viva_2020.pdf Acesso em: 20/09/2020.

FERNÁNDEZ, Francisco Moreno. El Español en Brasil. In: SEDYCIAS, João (Org.).O Ensino do Espanhol no Brasil: passado, presente, futuro. SãoPaulo: Parábola Editorial, 2005.

GONZÁLEZ, N. M. A lei 11.161, as Orientações Curriculares e as políticas públicas de formação de professores: a história de um descompasso entre o dizer e o fazer. V Congresso Brasileiro de Hispanistas / I Congresso Internacional da Associação Brasileira de Hispanistas, 2008, Belo Horizonte. Anais - V Congresso Brasileiro de Hispanistas / I Congresso Internacional da Associação Brasileira de Hispanistas, 2008.

TEACHING ENGLISH. O ensino de inglês na Educação Pública Brasileira. $1^{\text {a }}$ Edição. São Paulo, 2015. Elaborado pelo Instituto de Pesquisas Plano CDE. Disponível em: < https://www.britishcouncil.org.br/sites/default/files/estudo_oensinodoinglesnaeducacaopublic 
abrasileira.pdf> Acesso em: 20/09/2020.

TEACHING ENGLISH. Demandas de aprendizagem de inglês no Brasil. $1^{a}$ Edição. São Paulo, 2014. Elaborado pelo Instituto de Pesquisa Data Popular. Disponível em:

$<$ https://www.britishcouncil.org.br/sites/default/files/demandas_de_aprendizagempesquisaco mpleta.pdf > Acesso em: 20/09/2020. 